\title{
LICENCIAMENTO AMBIENTAL DE LOTEAMENTOS URBANOS NO
}

\section{MUNICÍPIO DE CAÇADOR/SC}

Tatiana Kazmierczak ${ }^{1}$

Daniely Andressa da Silva²

Éverton Bendlin Collet ${ }^{3}$

\section{RESUMO}

Este artigo aborda os aspectos legais do licenciamento ambiental de loteamentos no município de Caçador/SC. Têm por objetivo relatar as fases do licenciamento ambiental junto ao órgão ambiental estadual (FATMA), as características legais para a implantação de loteamentos; competência do órgão licenciador e da concessão das licenças prévia, de instalação e operação; prazos de validade e análise para a concessão das licenças; e os estudos ambientais exigidos. A pesquisa desenvolvida tem como público alvo, o poder público e a parte privada, como empresas e ao povo comum, para auxiliar na fiscalização, e incentivo ás empresas a atenderem as condicionantes e exigências do licenciamento. A metodologia adotada se dará através de pesquisas bibliográficas, leis, diretrizes em acervos digitais, baseando-se no método dogmático. Serão apontados ainda as características da implantação dos loteamentos conforme Lei Complementar no 89/06, que dispõe sobre o Plano Diretor, Lei Complementar no 128/08, que dispõe sobre o parcelamento do solo, e a Lei Complementar no 168/10, que dispõe sobre o zoneamento, todos do município de Caçador. A partir dos apontamentos legais conclui-se que o processo de licenciamento de loteamentos urbanos no município de Caçador é um importante instrumento para a gestão ambiental e execução do planejamento urbano, e que o compromisso de cumprimento da legislação deve ser adotado e respeitado por todos. As pessoas deveriam se preocupar mais com o meio ambiente, pensando em um ambiente ecologicamente equilibrado, socialmente junto e economicamente viável, não esquecendo que as gerações futuras também irão precisar dos recursos ambientais para sobreviver.

\footnotetext{
${ }^{1}$ Engenheira Ambiental - Universidade Alto Vale do Rio do Peixe (UNIARP), Especialização em Direito Ambiental (UNINTER).

2 Graduada em Direito pela Universidade Positivo e em Ciências Biológicas pela Universidade Federal do Paraná. Especialista em Ciências Jurídico Ambientais pela Faculdade de Direito da Universidade de Lisboa. Mestre em Direito (Ciências Jurídico- Ambientais) pela Faculdade de Direito da Universidade de Lisboa. Advogada. Professora universitária ministrando as disciplinas de Direito Ambiental, Direito Urbanístico, Direito Empresarial e Direito Público.

${ }^{3}$ Engenheiro Ambiental - Universidade Alto Vale do Rio do Peixe (UNIARP).
} 
Palavras-chave: Licenciamento ambiental. Loteamentos. Desenvolvimento sustentável.

\section{INTRODUÇÃO}

As questões relativas ao bem estar da humanidade e a expansão urbana estão tendo cada vez mais ênfase quando se discorre a respeito do desenvolvimento urbano sustentável, uma vez que o planejamento da ocupação do solo tem por base a harmonia entre os aspectos sociais, econômicos e ambientais, levando em consideração a aplicação da gestão dos recursos ambientais e o ordenamento territorial sobre as cidades (CETESB, Sustentabilidade e Desenvolvimento Urbano, 2016).

Como meio de mitigação dos impactos ambientais, se adota a aplicação dos instrumentos da Política Nacional do Meio Ambiente - Lei n 06.938 de 31 de agosto de 1981, Art. 9o dentre os quais estão o licenciamento e a revisão de atividades efetiva ou potencialmente poluidoras, avaliação de impactos ambientais, e o zoneamento ambiental.

Conforme disposto na Resolução do CONAMA 237/97, art. 10 parágrafo I, o licenciamento é um procedimento administrativo pelo qual o órgão ambiental responsável licencia a localização de determinado empreendimento que tem por base alguma atividade potencialmente poluidora, emitindo a liberação em forma de licença prévia, de instalação e operação.

O parcelamento do solo poderá ser em forma de loteamentos ou desmembramentos, conforme Lei no 6.766 de 19 de dezembro de 1979, Art. 2ㅇ․ E de acordo com a Resolução CONSEMA 13/2012 são atividades passíveis de licenciamento ambiental.

Este trabalho tem como objetivo geral abordar sobre a natureza jurídica do licenciamento ambiental de loteamentos urbanos no município de Caçador junto a Fundação do Meio Ambiente - FATMA, e as diretrizes municipais para o parcelamento do solo, de forma a caracterizar as etapas do licenciamento; as características legais para a implantação de loteamentos; competência do órgão licenciador e da concessão das licenças; prazos de validade e análise para a concessão das licenças; estudos ambientais exigidos. 
A pesquisa desenvolvida tem como público alvo, o poder publico e a parte privada, como empresas e ao povo comum, para auxiliar na fiscalização, e incentivo ás empresas a atenderem as condicionantes e exigências do licenciamento.

A metodologia adotada se baseia em pesquisas bibliográficas, leis, diretrizes em acervos digitais, a partir do método dogmático.

\section{DIRETRIZES LEGAIS DO LICENCIAMENTO AMBIENTAL E PARCELAMENTO DO SOLO}

URBANO

Conforme Constituição Federal de 1988, em seu Art. 182o o Plano Diretor do município é o instrumento básico da política de desenvolvimento e de expansão urbana, a qual tem o objetivo de ordenar integralmente o desenvolvimento das funções sociais da cidade e garantir o bem-estar de seus habitantes.

A função social da cidade abrange a mobilidade urbana, o acesso a moradia digna, implicando na universalização dos ambientes e de políticas urbanas específicas, como o Plano Diretor do município conforme Estatuto da Cidade, Art. 40 inciso III (PERCHE, 2014).

\section{O LICENCIAMENTO AMBIENTAL}

Segundo o Caderno de Licenciamento Ambiental do Ministério do Meio Ambiente - Programa Nacional de Capacitação de Gestores, 2009 [...] "a Constituição Federal de 1988 estabeleceu diversos serviços comuns a todas as esferas da federação, entre eles a parte sobre a preservação do meio ambiente".

A Gestão ambiental é um dos instrumentos do licenciamento ambiental e pode ser entendida como o processo de influência de interesses e conflitos entre fatores sociais que agem sobre os meios físico, natural e artificial, que tem por objetivo garantir o direito de todos sobre um meio ambiente ecologicamente equilibrado bem de uso comum do povo e a essencial á sadia qualidade de vida, e impõe ao poder público e a coletividade de defendê-lo e preservá-lo para as presentes e futuras gerações, conforme determina o Art. 225 da Constituição Federal de 88 (Série Educação Ambiental, ICMBIO, 2006, p. 41).

Assim, União, Estados, Distrito Federal e municípios têm o comum 
dever/poder de proteger o meio ambiente. Não existe uma hierarquia entre os entes federativos, tais entes possuem autonomia entre si (Programa Nacional de Capacitação de Gestores, 2009, p.21).

Segundo os instrumentos da Política Estadual Do Meio Ambiente, Capítulo I Do Licenciamento Ambiental, Seção I Das Atividades Sujeitas ao Licenciamento Ambiental, Art. 29. são passíveis de licenciamento ambiental pelo Órgão Estadual de Meio Ambiente as atividades consideradas, por meio de Resolução do CONSEMA, potencialmente causadoras de degradação ambiental.

Conforme a Resolução CONSEMA 13 de 21 de dezembro de 2012 a qual aprova a Listagem das Atividades Consideradas Potencialmente Causadoras de Degradação Ambiental passíveis de licenciamento ambiental no Estado de Santa Catarina e a indicação do competente estudo ambiental para fins de licenciamento, das atividades constantes do Anexo I da Resolução supracitada.

Assim, a atividade de Parcelamento do solo urbano: Loteamentos urbanos no município de Caçador/SC se enquadra no código 71 - Atividades Diversas, mais especificamente:

71.11.00 - Parcelamento do solo urbano: Loteamento e/ou condomínio de terrenos, localizado em municípios da Zona Costeira, assim definidos pela legislação específica, ou em municípios onde se observe pelo menos uma das seguintes condições: a) não possua Plano Diretor; b) não exista sistema de coleta e tratamento de esgoto na área objeto do parcelamento. Loteamento e/ou condomínio horizontal unifamiliar com área superior a 100ha, dependem obrigatoriamente de licenciamento, independente da localização (CONSEMA 13/2012).

Esta atividade possui como características de Parâmetro Técnico / Porte a relação com a área útil, o que quer dizer que a área útil é tudo aquilo que está construído ou não, mas está ou será utilizado (Resolução CONSEMA 13/2012).

Conforme o Porte do empreendimento especificado na Tabela 1, será exigido um tipo de estudo ambiental para o licenciamento junto a FATMA.

Tabela 1. Relação do Parâmetro técnico e seu respectivo porte e estudo ambiental correspondente. 


\begin{tabular}{c|l|l}
\hline $\begin{array}{c}\text { Área Útil } \\
\text { (hectares) }\end{array}$ & \multicolumn{1}{|c}{ Porte } & \multicolumn{1}{c}{ Estudo Ambiental } \\
\hline \hline$A U<=1$ & Pequeno & EAS - Estudo Ambiental Simplificado \\
\hline $1<\mathrm{AU}<5$ & Médio & EAS - Estudo Ambiental Simplificado \\
\hline $\mathrm{AU}>=5$ & Grande & EAS - Estudo Ambiental Simplificado \\
\hline $\mathrm{AU}>100$ & Grande & EIA - Estudo de Impacto Ambiental \\
\hline
\end{tabular}

Fonte: Instrução Normativa 03 da FATMA.

O licenciamento ambiental é considerado um instrumento de controle ambiental, pois estabelece condicionantes para exercício de determinada atividade (Programa Nacional de Capacitação de Gestores, 2009).

Para Fink e Macedo (2002, p. 03) o licenciamento ambiental é conduzido pelo Poder Executivo, o qual "dentro de seu poder de regular o exercício de alguns direitos (poder de polícia), será realizado pelo órgão ambiental normativamente designado".

Considerado como um procedimento administrativo o licenciamento ambiental visa o desenvolvimento sustentável e a melhoria contínua, licencia a localização, a viabilidade prévia, de instalação e operação do empreendimento de acordo com a atividade que utilizam os recursos ambientais, consideradas efetiva ou potencialmente poluidoras ou que possam causar degradação ambiental, considerando as disposições legais e regulamentares e as normas técnicas aplicáveis ao caso (CONAMA 237/97, Art. 1o parágrafo I).

\section{COMPETÊNCIA DE LICENCIAR E A LICENÇA AMBIENTAL}

Nos termos da Resolução CONAMA 237/97, a competência legal para licenciar, emitir a licença à um empreendimento funciona de acordo com a abrangência dos impactos que a atividade a ser licenciada acarretará, conforme observa-se na Tabela 2.

Tabela 2. Abrangência dos impactos ambientais e sua respectiva competência em nível Federal, Estadual e municipal. 


\begin{tabular}{l|l}
\hline \hline Abrangência dos Impactos & Órgão Competente \\
\hline \hline Dois ou mais estados & IBAMA \\
\hline Dois ou mais municípios & FATMA - Órgão Estadual \\
\hline Local & FUNDEMA - Órgão Municipal \\
\hline
\end{tabular}

Fonte: Programa Nacional de Capacitação de Gestores, 2009, adaptado pela autora.

A licença ambiental é o ato administrativo, emitida pelo órgão ambiental competente (no caso de Santa Catarina a Fundação do Meio Ambiente - FATMA), a qual por sua vez estabelece controles e condicionantes ambientais que o empreendedor deverá obedecer como regra geral, sendo pessoa física ou jurídica (CONAMA 237/97, Art. 1을 parágrafo II). Caso não sejam cumpridas estas condicionantes, pode haver ensejo da cassação da licença, com responsabilização civil e administrativa, ou ainda até responsabilidade penal (FINK; MACEDO, 2002).

Conforme Decreto n 2.955 de 20 de janeiro de 2010, o qual estabelece os procedimentos para o licenciamento ambiental a ser seguido pela Fundação do Meio Ambiente - FATMA, inclusive suas Coordenadorias Regionais - CODAMs, e estabelece outras providências, a licença ambiental deve estar em local visível no local do empreendimento.

O CONAMA 237/97 em seu Art. 10o parágrafo VIII, § $1^{\circ}$ estabelece que,

[...] no procedimento de licenciamento ambiental deverá constar, obrigatoriamente, a certidão da Prefeitura Municipal, declarando que o local e o tipo de empreendimento ou atividade estão em conformidade com a legislação aplicável ao uso e ocupação do solo e, quando for o caso, a autorização para supressão de vegetação e a outorga para o uso da água, emitidas pelos órgãos competentes.

De acordo com o Código Catarinense, Lei 14.675 de 13 e abril de 2009, seção II das Modalidade do licenciamento, o Art. 36 estabelece que o licenciamento ordinário será efetuado por meio da emissão de Licença Ambiental Prévia - LAP, Licença Ambiental de Instalação - LAl e Licença Ambiental de Operação - LAO.

De acordo com Sampaio, Wold, Nardy (2003) e o Art. 8 da Resolução CONAMA 237/97, relatam que o poder público, no exercício de sua competência de controle, expedirá as seguintes licenças:

- Licença Prévia - LP ou LAP: concedida na fase preliminar do 
planejamento do empreendimento ou atividade contendo os requisitos básicos a serem cumpridos, observando os planos municipais, estaduais ou federais de uso do solo. Essa licença atestada a viabilidade ambiental do empreendimento. Apresenta como parte principal sendo a avaliação dos impactos ambientais da atividade que pretende ser instalada, e o diagnostico da área afetada. A LP não autoriza o início de das obras destinadas à implantação do empreendimento.

- Licença de Instalação - LI ou LAl: autoriza a instalação do empreendimento ou atividade de acordo com as especificações constantes na LAP e Projeto Executivo.

- Licença de Operação - LO ou LAO: autoriza a operação da atividade ou empreendimento, é o início da atividade e o funcionamento de seus equipamentos de controle de poluição conforme estabelecido na LAP e LAI.

O Art. 18 da Resolução do CONAMA 237/97 e o Art. 40 do Código Catarinense (Lei 14.675/09), estabelecem os prazos de validade de cada tipo de licença, que estará descrito no respectivo documento, sendo:

- LAP deverá respeitar como prazo no mínimo o que foi estabelecido no cronograma dos projetos apresentados ao órgão ambiental, não podendo ultrapassar a 5 (cinco) anos;

- LAl deverá respeitar como prazo no mínimo o que foi estabelecido no cronograma dos projetos apresentados ao órgão ambiental para a instalação do empreendimento, não podendo ultrapassar a 6 (seis) anos;

- LAO considera-se o que foi estabelecido nos planos de controle ambiental, sendo no mínimo, 4 (quatro) anos e, no máximo, 10 (dez) anos.

A LAP e LAl dependendo de seus prazos poderão ser prorrogados a validade, mas nunca ultrapassando os prazos máximos estabelecidos (Lei 14.675/09, Art. 40, parágrafo III, § 1ㅇ).

O empreendimento que possuir a LAO, deve estar atendo ao seu prazo de validade para solicitar a sua renovação, que deverá ser requerida com antecedência mínima de 120 (cento e vinte) dias antes de seu vencimento, o que resulta na prorrogação automática da licença até a manifestação definitiva do órgão ambiental competente (Lei 14.675/09, Art. 40, parágrafo III, § 4ํ). 
OS ESTUDOS AMBIENTAIS

Os Estudos Ambientais são apresentados na fase de Licença Ambiental Prévia - LAP ao órgão ambiental, tal estudo discorre sobre o funcionamento do empreendimento, sua localização, diagnóstico ambiental da área, elaboração de programas de controle ambiental e demais aspectos e possíveis impactos a serem gerados pela atividade a ser licenciada (Código Catarinense, Lei 14.675/2009, Art. 31).

Os estudos são necessários no processo de licenciamento e deverão ser realizados por profissionais habilitados, e estes que subscrevem os estudos como EIA/RIMA - Estudo de Impacto Ambiental/Relatório de Impacto Ambiental, ECA Estudo de Conformidade Ambiental, RAP- Relatório Ambiental Prévio, EAS - Estudo Ambiental Simplificado, entre outros estudos, são responsáveis pelas informações apresentadas, sujeitando-se às sanções administrativas, civis e penais (CONAMA 237/97, Art. 11).

As atividades que estão em operação sem licença e solicitam a emissão da Licença Ambiental de Operação - LAO, o rito do licenciamento ambiental exige que seja apresentado o ECA - Estudo de Conformidade Ambiental (Código Catarinense, Lei 14.675/2009, Art. 32), o qual deve apresenta o conteúdo mínimo:

- Diagnóstico atualizado do ambiente;

- $\quad$ Avaliação dos impactos gerados pela implantação e operação do empreendimento, incluindo riscos;

- Medidas de controle, mitigação, compensação e de readequação, se couber.

Conforme Termo de referência constante na Instrução normativa - IN 03 da FATMA, o EAS é um estudo técnico elaborado por equipe multidisciplinar, deve abordar os aspectos do meio físico, biológico e sócio-econômico concluindo com um diagnóstico da área e atestando se há viabilidade ou não da implantação do empreendimento no local em que o estudo foi realizado e levantado as informações. Esse documento será a base para nortear as ações mitigadoras e os programas ambientais a serem implantados (Instrução Normativa da FATMA no 03). O Termo de referência da IN 03 da FATMA faz um check-list das informações básicas que o EAS deve contemplar, sendo: 

a) Objeto do licenciamento
b) Justificativa do empreendimento
c) Caracterização do empreendimento
d) Diagnóstico Ambiental Preliminar da Área de Influência
e) Identificação dos Impactos Ambientais
f) Medidas Mitigadoras e Compensatórias
g) Programas Ambientais
h) Equipe Técnica
i) Bibliografia

Como complementação dos estudos para o licenciamento, os responsáveis pela geração de resíduos sólidos ficam obrigados a elaborar o Plano de Gerenciamento de Resíduos Sólidos - PGRS, de acordo com o estabelecido na Lei no. 14.675/09, Art. 265.

\section{O VALOR DA ANÁLISE}

O processo de licenciamento ambiental envolve custos/despesas como qualquer outra atividade, sendo estas a contratação de profissionais habilitados para a elaboração dos estudos ambientais exigidos; publicações da imprensa dos atos relacionados ao processo do licenciamento; despesas relativa a implementação dos programas ambientais e medidas mitigadoras propostas no ato do licenciamento; o custo da análise do órgão ambiental/licenciador (Cartilha de Licenciamento Ambiental, Tribunal de Contas da União, 2007).

O valor de cada análise para a obtenção da licença, depende do potencial poluidor e/ ou porte do empreendimento, o qual está determinado na Resolução CONSEMA 13/2012, esse valor é fixo para cada um dos tipos de licença ambiental (LP, LI, LO).

Observa-se na Tabela 3 a relação entre o porte do empreendimento e o potencial poluidor/degradador geral, o que resulta no parâmetro para avaliação do valor a ser cobrado pelo órgão licenciador.

Tabela 3. Relação do Porte do empreendimento com o Potencial Poluidor/Degradador Geral 


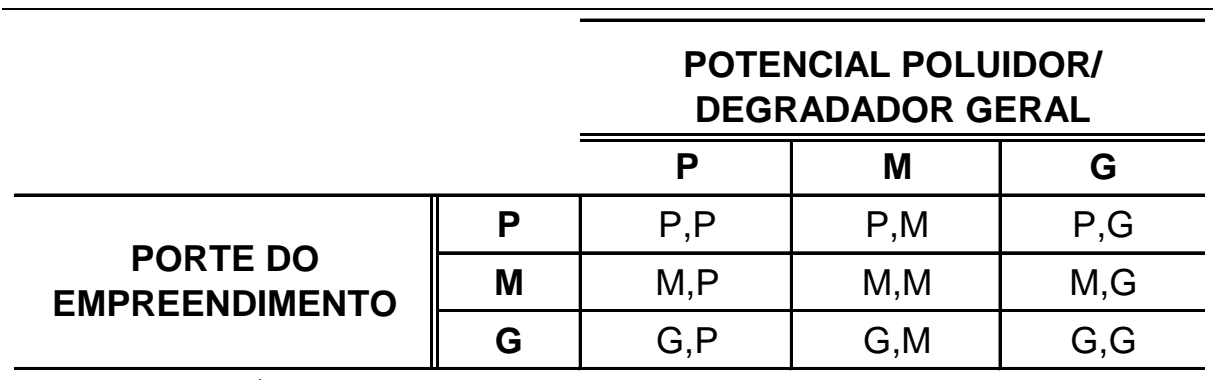

Fonte: Lei 14.262/2007.

Em Santa Catarina o valor estabelecido pela FATMA para análise dos processos de serviços ambientais está constituído na Lei no 14.262 de 21 de dezembro de 2007. Ressalta-se o disposto no Art. 13 da Resolução CONSEMA 237/97, "o custo de análise para a obtenção da licença ambiental deverá ser estabelecido por dispositivo legal, visando o ressarcimento, pelo empreendedor, das despesas realizadas pelo órgão ambiental competente".

DO TEMPO PARA ANÁLISE

Referente ao Tempo para análise do processo de licenciamento junto ao órgão ambiental, a Resolução CONSEMA 237/97, Art. 14 estabelece que o órgão ambiental competente poderá estabelecer prazos de análise diferentes para cada tipo de licença, levando em consideração as peculiaridades da atividade ou empreendimento, e as possíveis exigências extraordinárias que podem surgir, desde que observado o prazo máximo de 6 (seis) meses a contar do protocolo constante no recibo de documentos, a não ser que houver EIA/RIMA e/ou audiência pública, quando o prazo será de até 12 (doze) meses.

De acordo com o Código Catarinense - Lei 14.675/09, Art. 35 quando ocorrer a situação em que o processo solicitado de licenciamento tiver a decisão de indeferimento, cabe recorrer como recurso administrativo junto á FATMA no prazo de 20 (vinte) dias, a contar da data da ciência da decisão, que se dará por meio de Ofício de indeferimento entregue por intermédio de carta com Aviso de Recebimento - AR ou diretamente ao empreendedor ou seu representante legal pelo protocolo da FATMA (Decreto no 2.955/10, Art. 50). 


\section{PARCELAMENTO DO SOLO NO MUNICÍPIO DE CAÇADOR/SC: LOTEAMENTOS}

\section{URBANOS}

\section{LEI COMPLEMENTAR № 128/08}

De acordo com Toshio (2006, p. 367) "o parcelamento do solo é o processo de urbanização de uma gleba, mediante divisão em parcelas distintas ao exercício das funções elementares urbanísticas".

É atribuição do município, dirigir uma lei de parcelamento do solo de forma a fixar as normas urbanísticas específicas, atendidas as peculiaridades locais, estas leis municipais também deverão impor penalidades, prazos e procedimentos para aprovações de parcelamento em área urbana (TOSHIO, 2006).

A Lei Complementar no 128 de 12 de maio de 2008, estabelece as Normas para o parcelamento do solo para fins urbanos no Município de Caçador/SC.

Conforme Lei Complementar no 89 de 16 de outubro de 2006 - Institui o Plano Diretor do município de Caçador/SC e dá outras providências, Art. 86 é competência do Instituto de Pesquisa e Planejamento Urbano de Caçador - IPPUC, executar a Política Municipal de Planejamento Urbano, através da aplicação do que estará definido nas diretrizes legais para o uso e ocupação do solo.

Fiorillo (2005) entende que o plano diretor é uma determinação constitucional, é um instrumento básico do desenvolvimento e da expansão urbana. A propriedade urbana irá desempenhar sua função social quando atender as exigências estabelecidas no plano diretor. O Plano diretor deve ser aprovado pela câmara municipal e é obrigatório para municípios com mais de 20 (vinte) mil habitantes.

A licença prévia emitida pela prefeitura tem prazo de validade por 12 (doze) meses, passível de renovação por no máximo mais 12 (doze) meses desde que não tenha ocorrido alteração nas normas legais que as fundamentaram. Um dos requisitos para a emissão da LAP tanto da prefeitura como da FATMA é a viabilidade da Companhia Catarinense de Águas e Saneamento - CASAN de abastecimento de água potável para o local da implantação do loteamento (Lei Complementar no 128/08, Art. 8 § 1으 e 2으). 
A Prefeitura Municipal tem o prazo de até 60 (sessenta) dias a partir da data do protocolo, para deferir ou indeferir o projeto apresentado, tal prazo pode se prorrogado por mais 30 dias, a critério da Administração Municipal. Se houver solicitação de providências e/ou informações complementares, o prazo será suspenso e quando for protocolado os documentos solicitados começa a contar novamente o prazo. $O$ interessado tem 15 (quinze) dias para atender a pedido de informações complementares do projeto, podendo essa data ser prorrogada, caso não seja atendido ao solicitado pelo órgão municipal o processo está sujeito a arquivamento (Lei Complementar no $128 / 08$, Art. 10 § 1으 e 2으).

Quando o processo é deferido, o Chefe do Poder Executivo ira expedir um Decreto de aprovação do projeto de loteamento (Lei Complementar no 128 de 12 de maio de 2008, Art. 12). O interessado deverá submeter ao registro imobiliário em 180 (cento e oitenta) dias o projeto aprovado, sob pena de caducidade do ato (Lei Complementar no 128/08, Art. 14).

Após a conclusão das obras do loteamento, deverá ser comunicada a prefeitura que após vistoria "in loco" expedirá um Certificado de Conclusão de Obras de Urbanização (Lei Complementar no128/08, Art. 15).

O loteamento está submetido a fiscalização tanto da prefeitura como da FATMA e outros órgãos ambientais competentes, quando da execução dos serviços e obras de infraestrutura urbana, sendo assim todas as solicitações emitidas por esses órgãos deverão ser atendidas, sob pena de embargo da obra (Lei Complementar no $128 / 08$, Art. 17 § 1ㅇe e 2으).

Conforme disposto na Lei Estadual no 6.063 de 24 de maio de 1982, Art. 8, os projetos de loteamento deverão seguir os seguintes requisitos:

I - as áreas destinadas a sistema de circulação, a implantação de equipamento urbano e comunitário e espaços livres de uso público, não poderão ser inferiores a 35\% (trinta e cinco por cento) da gleba;

II - os lotes terão área mínima de $125 \mathrm{~m}^{2}$ (cento e vinte e cinco metros quadrados) e frente mínima de 5 (cinco) metros, salvo quando a legislação municipal determinar maiores exigências, ou quando o loteamento se destinar à urbanização específica ou edificação de conjuntos habitacionais de interesse social, previamente aprovados pelos órgãos públicos competentes; (Redação alterada pela Lei no 10.957/98)

III - ao longo das águas correntes e dormentes e das faixas de domínio público das rodovias, ferroviárias e dutos, é obrigatória a reserva de uma faixa "non aedificandi" de 15 m (quinze metros) de cada lado, 
salvo maiores exigências estabelecidas em lei federal ou municipal.

Segundo a Lei Municipal de Caçador sobre o Parcelamento do Solo os loteamentos localizados junto as Rodovias Estadual e Municipal deverão respeitar a faixa de 14,0 m de largura para cada lado (Lei Complementar no 128/08, Art. $25 \S$ 3ㅇ).

Da implantação de um loteamento - parcelamento do solo, deve ser respeitado as área de uso comum, as quais asseguram o pleno desenvolvimento das funções sociais da cidade e da propriedade urbana, o que acaba levando em consideração o lazer, a infraestrutura e a integração entre o homem e a natureza, sendo assim constituído pela área verde, a qual corresponde a espaços de domínio público, com a função de desempenhar a função ecológica, paisagística e recreativa do loteamento; área institucional, destinada a edificação de equipamento á comunidade em geral, como ginásios e parques; área de arruamento, a qual corresponde as vias de circulação (Guia de Atuação no Ordenamento Territorial e Meio Ambiente, MPSC, 2015).

Dessa Forma ficam estabelecidas pelo Plano de Parcelamento do Solo do Município e Plano Diretor as diretrizes que o loteamento deve obedecer. Através da Figura 1 pode-se ter uma noção de como é dividido essas áreas supracitadas em um projeto de loteamento urbano.

Figura 1. Demonstrativo de uma parte de um projeto de loteamento urbano.

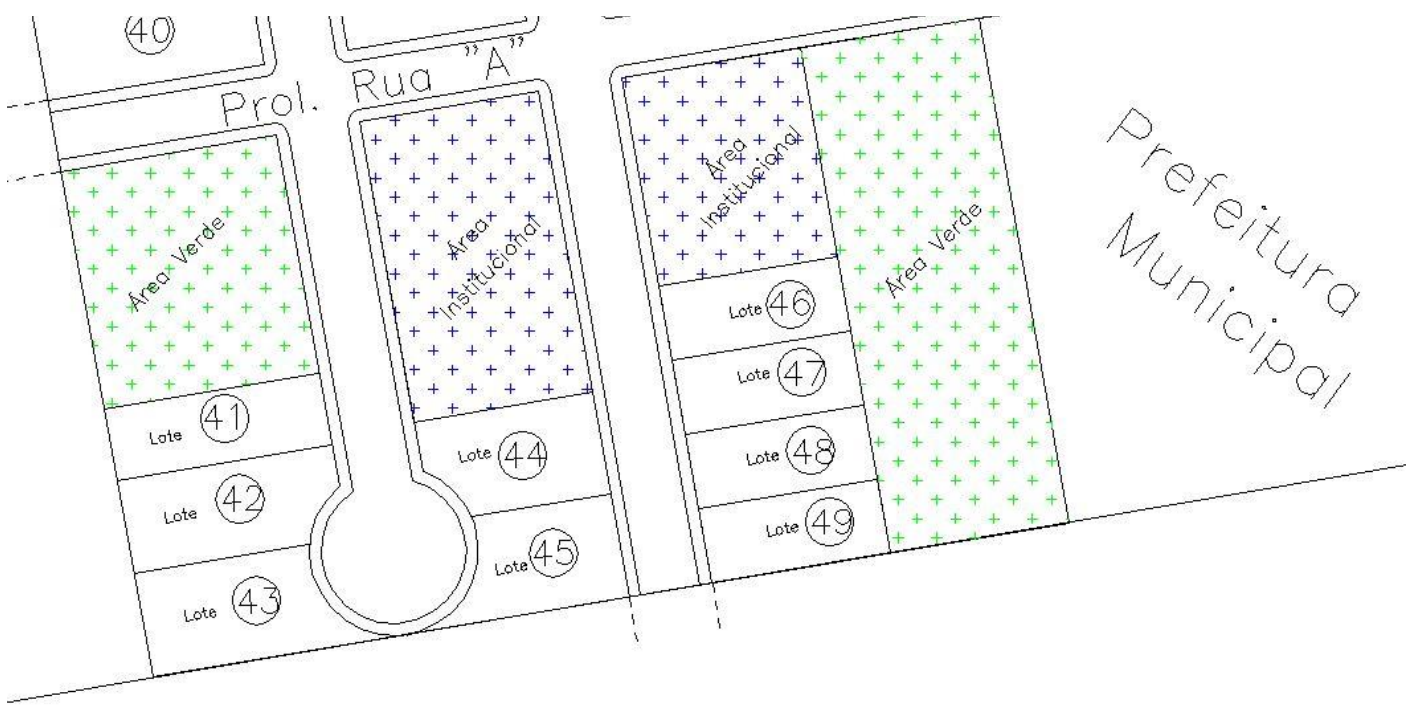

Fonte: autoria própria. 
Das Normas Técnicas do parcelamento do solo municipal segundo a Lei 128/08, Art. 22, não são permitidos:

I - em terrenos alagadiços e sujeitos a inundações, antes de tomadas as providências para assegurar o escoamento das águas;

II - em terrenos que tenham sido aterrados com material nocivo à saúde pública, sem que sejam previamente saneados;

III - em terreno com declividade igual ou superior a 30\% (trinta por cento), salvo se atendidas exigências específicas das autoridades competentes;

IV - em terrenos onde as condições geológicas não aconselham a edificação;

V - em áreas de preservação ecológica, ou naquelas onde a poluição impeça condições sanitárias suportáveis, até sua correção;

$\mathrm{VI}$ - em terrenos situados nas Zonas de Interesse Ambiental, conforme estabelecido na lei de Zoneamento, Uso e Ocupação do Solo Urbano.

De acordo com a Lei Complementar no 128/08 Art. $26 \S 1$ 으 e Art. 29, o acesso a qualquer loteamento deverá conter no mínimo 12,0 (doze) metros de largura, e o comprimento das quadras não poderá ser superior a 260,0 (duzentos e sessenta) metros.

Ainda segundo a Lei Complementar no 128/08 Art. 49 nos loteamentos serrão obrigatórios os seguintes serviços e obras de infra- estrutura urbana:

I - demarcação das quadras, lotes, logradouros e vias de circulação [...];

II - abastecimento de água potável [...];

II - rede de distribuição de energia elétrica pública e domiciliar e iluminação pública de acordo com o tipo da via do loteamento, observando:

a) nas vias normais deverá ser instalado posteamento padrão CELESC e iluminação pública em todos os postes com capacidade de lumes não inferior a 70 watts por poste, em vapor de sódio ou mais eficiente em relação ao fluxo luminoso/potência;

b) nas ruas e avenidas classificadas como eixos viários principais, anéis viários e eixos viários complementares (vias arteriais e coletoras) deverá ser instalado o mesmo tipo de posteamento indicado acima, e luminárias fechadas de 250 watts (vapor de sódio) ou mais eficiente em relação ao fluxo luminoso/potência;

IV - terraplanagem e pavimentação de todas as ruas do loteamento [...];

$\mathrm{V}$ - equipamentos urbanos de escoamento das águas pluviais [...];

$\mathrm{VI}$ - arborização dos passeios e dos canteiros das avenidas [...];

VII - construção de encostas, quando necessário;

VIII - recobrimento vegetal de cortes e taludes do terreno;

IX - equipamento urbano constante da tubulação e complementos necessários para implantação de esgoto sanitário [...]. 
Dessa forma com as especificações na legislação municipal, que vem a complementar as leis federais, e/ou estaduais, de acordo com a realidade local, viabilizando a implantação dos loteamentos em cada situação, município e região. Cumprindo assim o especificado na CF 88, art. 30, que rege sobre a competência dos municípios, de promover o ordenamento territorial, mediante planejamento.

\section{PLANO DE ZONEAMENTO - LEI COMPLEMENTAR № 168/10}

Conforme Lei Complementar no 89 de 16 de Outubro de 2006, o qual institui o Plano Diretor do Município de Caçador e dá outras providências, Art. 7, parágrafo III, fica estabelecido entre seus objetivos gerais "promover o desenvolvimento sustentável, a equidade social e ampliar o acesso da população a bens, serviços, trabalho e geração de renda". Ainda, conforme Art. 3, parágrafo I, fazem parte do planejamento municipal a disciplina do parcelamento, do uso e da ocupação do solo assim como o zoneamento ambiental.

O Zoneamento ambiental nas palavras de José Afonso da Silva "é um procedimento urbanístico, que tem por objetivo regular o uso da propriedade do solo em área homogêneas no interesse coletivo e bem estar da população". Tratase de uma limitação administrativa de direito da propriedade, considerando que o solo deve ser utilizado com base no principio da função social. (SIRVINKAS, 2007).

O Zoneamento do Município de Caçador se dá através da Lei Complementar no 168, de 16 de abril de 2010, a qual dispõe sobre o Zoneamento, o Uso e a Ocupação do Solo do Município de Caçador e dá outras providências. Conforme o Art. 2 esta Lei dispõe sobre o compartimento e divisão das macrozonas da Área Urbana da Cidade de Caçador e estabelece critérios e parâmetros de uso e ocupação do solo, com o objetivo de orientar e ordenar o crescimento da cidade, buscando a utilização do solo em função do sistema viário, da topografia e da infraestrutura existente, através da criação de zonas e setores de uso e ocupação do solo e adensamentos diferenciados.

Os critérios para definição das zonas, uso e ocupação do solo atendem a Política de Estruturação Urbana e do Uso do Solo para a Área Urbana da Cidade de Caçador, definidos no Plano Diretor (Art. 3, Lei Complementar no 168/2010). A delimitação das zonas e dos setores são determinados por vias, logradouros públicos, acidentes topográficos, divisas de lote e referências de distâncias em 
relação às vias, conforme indicado em mapa integrante desta Lei Complementar no 168/2010, conforme exposto no $\S 1$ 으 e $\S 2$ o do Art. 2.

Os Art. 6 e 17 da Lei Complementar no 168/2010 relatam sobre os usos do solo que se fundamentam na compatibilidade das características da vizinhança, e se classificam da seguinte forma:

1) habitacional: uso destinado à moradia, sendo dividida em:

a) unifamiliar - HU, que abrange apenas uma moradia por lote;

b) multifamiliar vertical - HMV, composto por mais de uma unidade habitacional por lote.

2) não habitacional: uso destinado ao exercício de atividades comerciais, de serviços, industriais e/ou institucionais;

3) misto: uso destinado com mais de uma atividade dentro de um mesmo lote, por exemplo: residencial e comercial.

De acordo com a Lei Complementar no 168/10, Art. 7, as zonas no município de Caçador ficam subdivididas conforme Figura 2:

Figura 2. Especificações e siglas das divisões das zonas do município de Caçador/SC.

\begin{tabular}{l|c}
\hline Especificação & Sigla \\
\hline \hline Zona Central & ZC \\
\hline Setores Estruturantes & SE \\
\hline $\begin{array}{l}\text { Zonas Residenciais de Baixa e Média } \\
\text { Densidade }\end{array}$ & ZR \\
\hline Zonas Especiais de Interesse Social & ZEIS \\
\hline Zonas de Interesse Ambiental & ZIA \\
\hline Zonas de Recuperação Urbana & ZRU \\
\hline Zonas de Expanção Urbana & ZEU \\
\hline Zonas Industriais & ZI \\
\hline Zonas de Serviços & ZS \\
\hline Zona Aeroportuária & ZA \\
\hline
\end{tabular}

Fonte: Lei complementar no 168/10, art.70, adaptada pela autora.

Ainda considera-se em cada zona ou setor a categoria de porte e 
natureza, como:

I - permitidas: compreendem as atividades que apresentem clara compatibilidade com as finalidades urbanísticas da zona ou setor correspondente;

II - permissíveis: compreendem as atividades cujo grau de adequação à zona ou setor dependerá da análise ou regulamentação específica para cada caso;

III - proibidas: compreendem as atividades que, por sua categoria, porte ou natureza, são nocivas, perigosas, incômodas e incompatíveis com as finalidades urbanísticas da zona ou setor correspondente.

O zoneamento é uma medida de ordem publica, ou seja há a distinção de zonas do município mediante consulta á população, por meio da Administração pública. Apresenta como objetivo arbitrar e definir os usos possíveis da utilização do solo, com o estabelecimento de zonas em microrregiões (ANTUNES, 2008).

\section{CONSIDERAÇÕES FINAIS}

A partir dos apontamentos feitos, pode-se concluir que o processo de licenciamento de loteamentos urbanos no município de Caçador é um importante instrumento para a gestão ambiental e execução do planejamento urbano.

O licenciamento de loteamentos em Caçador se dá por meio de autorização emitida pelo órgão ambiental estadual (já que o órgão ambiental municipal não tem autorização para licenciar loteamentos), através da licença ambiental prévia, de instalação e operação as quais estabelecem medidas compensatórias, preventivas, condicionantes e condições específicas, buscando os menores impactos possíveis ao meio ambiente. Tais licenças devem estar de acordo com a fase em que se encontra o empreendimento.

De maneira geral, o Estatuto da Cidade define o Plano Diretor como sendo o principal instrumento de planejamento urbano dos municípios, e demarca as diretrizes a serem seguidas em suas políticas públicas de desenvolvimento, determinando que as cidades exerçam a sua função social de maneira inclusiva e demográfica.

De acordo com o levantamento das legislações, estes demonstraram que o município de Caçador possui um Plano Diretor, Lei de Parcelamento e Ocupação do solo, assim como o Plano de Zoneamento os quais são instituídos no município 
para que haja a organização do espaço urbano de acordo com o potencial da região em específico, de forma a atender as necessidades da sociedade nela presente, considerando os aspectos sociais, econômicos e ambientais. Dessa forma o compromisso de cumprimento da legislação deve ser adotado e respeitado por todos.

Deste modo, os instrumentos legais abordados neste artigo devem ser entendidos e aplicados corretamente levando em consideração o desenvolvimento sustentável de todo o município.

Assim é preciso que haja a adequação da legislação municipal de acordo com a evolução local, buscando a adaptação de cada situação.

Destarte, se faz necessária a compreensão das leis ambientais dentro do contexto de responsabilidade, sendo que as pessoas deveriam se preocupar mais com o meio ambiente, pensando em um ambiente ecologicamente equilibrado, socialmente junto e economicamente viável, não esquecendo que as gerações futuras também irão precisar dos recursos ambientais para sobreviver.

\section{REFERÊNCIAS}

ANTUNES, Paulo de Bessa. Direito Ambiental. 11a ed. amplamente reformulada. Editora Lumen Juris. Rio de Janeiro, 2008.

BRASIL. Lei $\mathrm{n}$ 0 6.938, de 31 de agosto de 1981. Dispõe sobre a Política Nacional do Meio Ambiente, seus fins e mecanismos de formulação e aplicação, e dá outras providências. Disponível em:

<http://www.planalto.gov.br/ccivil_03/leis/L6938.htm>. Acessado em 19 de jul. 2016.

. Lei no 6.766, de 19 de dezembro de 1979. Dispõe sobre o Parcelamento do Solo Urbano e dá outras Providências. Disponível em:

<http://www.planalto.gov.br/ccivil_03/leis/L6766.htm>. Acessado em 19 de jul. 2016.

.Constituição da Republica Federativa do Brasil de 1988. Disponível em: <http://www.planalto.gov.br/ccivil_03/constituicao/constituicaocompilado.htm>. Acessado em 19 de jul. 2016.

. Resolução CONAMA 237, de dezembro de 1997. Disponível em: 
<http://www.mma.gov.br/port/conama/res/res97/res23797.html>. Acessado em 19 de jul. 2016.

Resolução CONSEMA 13 de 21 de dezembro de 2012. Disponível em:

<http://www.abetre.org.br/biblioteca/publicacoes/publicacoesabetre/ResoluoCONSEMAn13retificada.pdf>. Acessado em 19 de jul. 2016.

Caçador (Município). Lei no 14.262, de 21 de dezembro de 2007. Dispõe sobre a Taxa de Prestação de Serviços Ambientais. Disponível em: <http://legislacao.sef.sc.gov.br/html/leis/2007/lei_07_14262.htm>. Acessado em 19 de jul. 2016.

. Lei Complementar no 128, de 12 de maio de 2008. Estabelece as Normas para o Parcelamento do Solo para fins Urbanos no Município de Caçador. Disponível em: <http://camara-municipal-decacador.jusbrasil.com.br/legislacao/960254/lei-complementar-128-08>. Acessado em 19 de jul. 2016.

. Lei Estadual no 6.063, de 24 de maio de 1982. Dispõe sobre o parcelamento do Solo Urbano e dá outras providencias. Disponível em: <http://www.deinfra.sc.gov.br/fxd/documentos/606382.pdf>. Acessado em 19 de jul. 2016.

Lei Complementar no 168, de 16 de abril de 2010. Dispõe sobre o Zoneamento, o Uso e a Ocupação do Solo do Município de Caçador e dá outras providências. Disponível em:

<http://www.cacador.sc.gov.br/portalhome/zoneamento/LeiComp16810Lei\%20de\%20Zoneamento.pdf>. Acessado em 19 de jul. 2016.

Lei Complementar no 89, de 16 de Outubro de 2006. Institui O Plano Diretor do Município de Caçador e dá outras Providências. Disponível em:< https://leismunicipais.com.br/a2/sc/c/cacador/lei-complementar/2006/8/89/leicomplementar-n-89-2006-institui-o-plano-diretor-do-municipio-de-cacador-e-daoutras-providencias>. Acessado em 19 de jul. 2016.

CETESC- SP. Sustentabilidade e Desenvolvimento Urbano: Ciclo de debates sobre construção civil sustentável. Disponível em:

<http://www.cetesb.sp.gov.br/noticentro/2007/11/claudio.pdf>. Acessado em 19 de jul. 2016.

FINK, Daniel Roberto. MACEDO, André Camargo Horta de. Aspectos Jurídicos do Licenciamento Ambiental: Capitulo I - Roteiro para licenciamento ambiental e outras 
considerações. Editora Forense Universitária. 2a ed. Rio de Janeiro, 2002.

FIORILLO, Celso Antonio Pacheco. Estatuto da cidade comentado: Lei 10.257/2001: Lei do Meio ambiente Artificial, Capitulo III do plano diretor. Editora Revista dos Tribunais. 2a ed revisada, atualizada e ampliada. São Paulo, 2005.

ICMBIO, Série Educação Ambiental. Introdução á Gestão Ambiental Pública.

Disponível em:

<http://www.icmbio.gov.br/educacaoambiental/images/stories/biblioteca/educaca o_ambiental/QUINTAS_Jos\%C3\%A9_Silva_-

_Introdu\%C3\%A7\%C3\%A30_\%C3\%A0_Gest\%C3\%A30_Ambiental_P\%C3\%BAblica.p df>. Acessado em 19 de jul. 2016.

Ministério do Meio Ambiente - MMA. Programa Nacional de Capacitação de Gestores: Caderno de Licenciamento Ambiental. Brasília. 2009.

Ministério Pública de Santa Catarina - MPSC. Guia de Atuação no Ordenamento Territorial e Meio Ambiente. Florianópolis. 2015.

MUKAI,Toshio. Direito Urbano e Ambiental. Editora Fórum. 3a ed. Belo Horizonte, 2006.

PERCHE, Amélia. As funções sociais da cidade e o direito ao meio ambiente equilibrado. Disponível em: <https://jus.com.br/artigos/34259/as-funcoes-sociaisda-cidade-e-o-direito-ao-meio-ambiente-equilibrado>. Acessado em 19 de jul. 2016.

Santa Catarina (Estado). Decreto no 2.955, de 20 de janeiro de 2010. Estabelece os procedimentos para o licenciamento ambiental a ser seguido pela Fundação do Meio Ambiente - FATMA, inclusive suas Coordenadorias Regionais - CODAMs, e estabelece outras providências. Disponível em: $<$ http://server03.pge.sc.gov.br/LegislacaoEstadual/2010/002955-005-0-2010002.htm>. Acessado em 19 de jul. 2016.

. Lei no 14.675, de 13 de abril de 2009. Institui o Código Estadual do Meio Ambiente e estabelece outras providências. Disponível em: <http://www.institutohorus.org.br/download/marcos_legais/Lei\%2014.675\%20Co digo_ambiental_SC.pdf>. Acessado em 19 de jul. 2016.

.Instrução Normativa 03 da FATMA. Dispõe sobre Parcelamento do solo urbano: loteamento ou condomínio de terrenos Loteamento com fins industriais e comerciais. Disponível em: 
<http://www.fatma.sc.gov.br/ckfinder/userfiles/arquivos/ins/03/IN\%2003\%20Parc elamento\%20do\%20solo.pdf>. Acessado em 19 de jul. 2016.

SAMPAIO, José Adércio Leite. WOLD, Chris. NARDY, Afrânio José Fonseca. Princípios do Direito Ambiental na Dimensão Internacional e Comparada. Belo Horizonte: Del Rey, 2003.

SIRVINSKAS, Luís Paulo. Manual do Direito Ambiental. Editora Saraiva. 5a Ed. revisada e atualizada. São Paulo, 2007.

Tribunal de Contas da União. Cartilha de Licenciamento Ambiental. 2a edição, Brasília. 2007. 